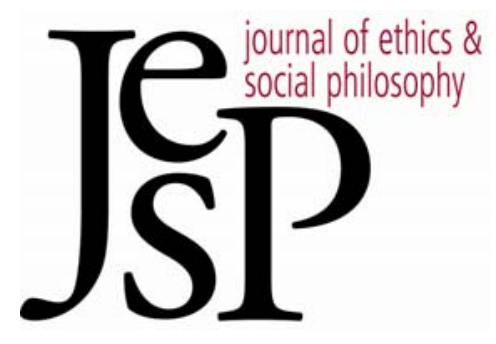

\title{
The Locative ANALYsis of Good FoR FoRMULATED AND DEFENDED
}

\author{
BY GUY FLETCHER
}

Journal of Ethics $\&$ Social Philosophy

Vol. 6, No. 1 | JANUARY 2012 URL: WWW.JESP.ORG COPYRIGHT (C GUY FLETCHER 2012 


\title{
The Locative Analysis of Good For Formulated and Defended
}

\author{
Guy Fletcher
}

\section{$\mathrm{T}$} HE STRUCTURE OF THIS PAPER IS AS FOLLOWS. I begin $\$ 1$ by dealing with preliminary issues such as the different relations expressed by the "good for" locution. I then ( $\$ 2)$ outline the Locative Analysis of good for and explain its main elements before moving on to $(\$ 3)$ outlining and discussing the positive features of the view. In the subsequent sections I show how the Locative Analysis can respond to objections from, or inspired by, Sumner (\$4-5), Regan (\$6), and Schroeder and Feldman (\$7). I then ( $\$ 8)$ reply to an imagined objector who claims that the Locative Analysis generates implausible results with respect to punishment, virtue and agent-centered duties.

\section{Introduction}

Before examining the Locative Analysis, it is necessary to deal with some background issues. The first of these is the different ways that we use the locution "good for" and the fact that we use it to express different relations. The good for relation that I am interested in here is that connected to well-being. ${ }^{1}$ A helpful initial characterization of this comes from Scanlon:

\footnotetext{
The intuitive notion of well-being that I am concerned with, then, is an idea of the quality of a life for the person who lives it that is broader than material and social conditions, at least potentially broader than experiential quality, different from worthiness or value, and narrower than choiceworthiness all things considered. ${ }^{2}$
}

Even if less than fully informative, these remarks give an approximate indication of the good for relation examined here. But there are many other ways in which we use the phrase "good for" that clearly do not express the same relation and it is helpful to distinguish these briefly.

Sometimes people use "good for" to express the relation of being good from the perspective of. There are at least two versions of this. One treats something's being good from the perspective of $\mathrm{X}$ as its being believed, by $\mathrm{X}$, to be good. We use this locution in belief ascriptions such as in: "The repeal of Obama's healthcare law is good for X," where we mean only to report that X believes the repeal to be, generally, good. This is not the relation I seek to analyze here. This is because it is only a belief that is relativized to $\mathrm{X}$ in this analysis (a belief about what is simply good). But this is not the same as saying that it would be good for X, that it would contribute positively to X's well-being.

A second way of spelling out good from the perspective of $X$ is as that which has agent-relative value for $\mathrm{X}$, or what $\mathrm{X}$ has reasons to adopt pro-

\footnotetext{
1 When talking about this relation I use the italicized good for.

2 Scanlon (1998: 113).
} 
attitudes towards. ${ }^{3}$ But this is not the same as the good for relation. Something that is good from the perspective of $\mathrm{X}$ need not be good for X. ${ }^{4}$ Your child's happiness might have agent-relative value for you without itself being good for you.

A third usage of "good for" to set aside is that found in sentences such as: "It would be good for X to run the department." This sentence can be parsed in at least two ways:

(a) It would be good $<$ for $\mathrm{X}$ to run the department $>$.

(b) It would be <good for $\mathrm{X}>$ to run the department.

Someone who asserts the original sentence could be making claim (a) or claim (b). The first is a claim about what is generally good. The second is a claim about what would be good for $\mathrm{X}$ in the sense connected to wellbeing. We can see this difference because if they utter the sentence with the emphasis as placed in (b) but went on to add - "but it would be bad for X, of course!" - we would find their utterance puzzling. They could, however, add this to the utterance with the emphasis in (a) without incoherence. They could just mean that although it would be bad for X herself, for her to run the department, the benefit to others would be too great to overlook. The good for relation that I am interested in here is that expressed by the sentence with emphasis placed as in (b), where the person means that it is good for X.

Having distinguished and set aside some of the things that we use "good for" to express, I now move on to discuss the nature of the relevant good for relation, that which is the positive side of well-being. ${ }^{5}$

\title{
2. The Locative Analysis
}

The origins of the Locative Analysis lie in Moore's discussion of "my own good":

\begin{abstract}
What, then, is meant by "my own good"? In what sense can a thing be good for me? [...] [W] hen I talk of a thing as "my own good" all that I can mean is that something which will be exclusively mine, as my own pleasure is mine (whatever be the various senses of this relation denoted by "possession"), is also good absolutely; or rather that my possession of it is good absolutely. The good of it can in no possible sense be "private" or be-
\end{abstract}

\footnotetext{
${ }^{3}$ Hurka (1987: 71): “Something is good from a person's point of view if she (and perhaps only she) ought morally to desire and pursue it."

4 For discussion of the good-from-the-perspective-of/good-for distinction, see Schroeder (2007a).

5 I have not set aside all of the others. I have highlighted only a selection of those most commonly confused with the good for relation under discussion here. One omission is the exclamation, "Good for you!" - used as a means of congratulating someone. Another is when someone evaluates according to a relativized standard, such as in, "This essay is good for an undergraduate." Yet another is Prichard's (1937: 174) claim that "If then, as seems clear, we mean by 'a good to us' something which directly or indirectly excites pleasure in us..."
} 
long to me; any more than a thing can exist privately or for one person only. ${ }^{6}$

From this passage we can extract a precursor to the Locative Analysis of good for: something's being good for me is simply its being good and mine. This faces a counterexample: If I come to possess something good, such as a beautiful vase, it is not true that this vase is itself good for me, despite it being good and mine. So something's being good for me cannot simply be it being good and it being mine in an unrestricted way. The Locative Analysis must be refined so as to avoid this problem. One refinement is the addition of the claim that a necessary condition of something's being good for a subject is that it is essentially related to them. However, as well as adding this refinement there is another clause of the analysis which it will be useful to make clear here. Thus in full the analysis is:

Locative Analysis of good for: $\mathrm{G}$ is non-instrumentally good for $\mathrm{X}$ if and only if (i) $G$ is non-instrumentally good, (ii) $G$ has properties that generate, or would generate, agent-relative reasons for $\mathrm{X}$ to hold pro-attitudes towards $G$ for its own sake, (iii) $G$ is essentially related to $X$.

I return to the details of this analysis and their motivation below but clarifications are needed at the outset in order to fill out the view and to preempt certain objections.

First, this is only an analysis of something's being noninstrumentally good for X. ${ }^{8}$ But it is easy to generate an account of what it is for something to be instrumentally good for X: To be instrumentally good for $\mathrm{X}$ is to have causal properties that can bring about something that is non-instrumentally good for X. Unless otherwise specified, all references to good for refer to the relation of being non-instrumentally good for.

Second, on clause (i), though it is more common for people to refer to intrinsic goodness when discussing non-instrumental goodness this presupposes a substantive view about value. I use "non-instrumentally good" to leave open the possibility that non-instrumental goodness may be either intrinsic (held in virtue of intrinsic properties of its bearer) or extrinsic (held in virtue of extrinsic properties of its bearer). ${ }^{9}$

Third, clause (i) of the analysis is in tension with those who deny that anything can be good simpliciter.10 The dispute between those who

\footnotetext{
6 Moore (1903: 150).

7 The analysis of bad for runs: $G$ is bad for $X$ if and only if (i) $G$ is non-instrumentally bad, (ii) $G$ has properties that generate, or would generate, agent-relative reasons for $X$ to hold con-attitudes towards $G$ for its own sake, (iii) $G$ is essentially related to $X$.

8 I reiterate this at the beginning of section 6.

${ }^{9}$ For discussion see Korsgaard (1983). Those who think all non-instrumental value is intrinsic value should be happy with this distinction even if they think it redundant. I use "non-instrumental" rather than "final" for ease of exposition because this allows one to make the same instrumental/non-instrumental distinction in reference both to that which is good and that which is good for. But if one thinks of final value as only a subset of non-instrumental value, then, to be clear, my clause (i) requires that the thing have final value. I discuss these issues in more detail in Fletcher (2008).

${ }^{10}$ This position is most associated with Geach (1956), Foot (2000) and Thomson (2003).

Part of the reason why the dispute is too big to get into here is that the status of the
} 
think that all goodness is attributive and their opponents is too large to get into here, so I only note that the analysis takes a side on this issue. ${ }^{11}$

Fourth, clause (ii) of the analysis only claims that being good for $\mathrm{X}$ generates, or would generate, agent-relative reasons for $\mathrm{X}$ to hold proattitudes towards the thing. ${ }^{12}$ I construe pro-attitudes narrowly here, so as to include desire and preference and similar states, but not promotion. This means that the Locative Analysis is compatible with the claim that all reasons to promote well-being are agent-neutral. ${ }^{13}$

Fifth, it might be suggested that the analysis is vulnerable to the "wrong kind of reason" problem. There is insufficient space to deal with that issue here but it is worth noting that the analysis says that it must be properties of $G$ itself that provide agent-relative reasons (a formulation which avoids some "wrong kind of reason" cases). Also, the "wrong kind of reason" problem is that of finding a way to explicate a distinction that we are comfortable with and able to make across a wide range of cases. The difficulty of doing this does not lead us to reject the distinction, nor does there seem any reason to do so. Finally, the "wrong kind of reason" problem also afflicts theories in the main alternative class buck-passing theories of good for - so the Locative Analysis is not the only analysis with work to do here.

Sixth, one might think that clause (ii) is vulnerable to cases such as the well-being of infants, for one might think that things can be good for them but doubt that they can have pro-attitudes and thus doubt that they can have reasons to have them. This would be a mistake. The formulation makes reference to properties that generate or would generate agentrelative reasons. This allows that something can be good or bad for someone even if they are unable to hold the relevant attitudes. If it is something with properties that would generate reasons for pro-attitudes if the person were in a position to hold such attitudes then the second clause is satisfied. An example of this is having reasons to hold proattitudes in adulthood towards aspects of one's infancy that were noninstrumentally good for one. Furthermore, even if a person in fact never has the capacity to hold pro-attitudes, because of congenital mental disability for example, we can still ask of some prudential good or bad whether it has properties that would generate reasons for the person to hold pro or con attitudes towards it if they had the capacity to bold such attitudes and the ability to respond to reasons to have them. The Locative Analysis does not require that people are able to hold the attitudes that they have

Geach-Foot-Thomson claim, and the means of deciding its truth or falsity, are not clear.

11 The analysis is also noncommittal with respect to what the ontological status of "G" is. This is in order to make it neutral between those who think that states of affairs are the bearers of prudential value and those who think otherwise.

${ }^{12}$ Hereafter I usually omit the "or would generate," for brevity.

13 This analysis is inconsistent with the claim that, with respect to well-being, all reasons to adopt pro-attitudes generally - desire included - are agent-neutral. But this is much more demanding, and counterintuitive, than the view that all reasons to promote wellbeing are agent-neutral. Thus the analysis makes well-being partly agent-relative (because it generates agent-relative reasons) but in a minimal, and plausible, way. 
agent-relative reasons to hold towards the things that are good for them at the time such goods are instantiated. It requires only that the things have properties that previously did, will or would generate such reasons for pro or con attitudes were the person capable of holding such attitudes and responding to reasons to have them. This is the full version of clause (ii).

Seventh, because the Locative Analysis treats clause (ii) as merely a necessary condition of something's being good for someone, the analysis can allow that $\mathrm{X}$ has agent-relative reasons to desire things that are not good for them - such as the well-being of their friend Y - without Y's well-being being good for X. This is because clause (iii) is not satisfied in such a case. ${ }^{14}$

Eighth, the Locative Analysis is not intended to be an analytic truth or a truth about the concept GOOD FOR. Rather, it is an analysis of the good for relation or property. Thus the Locative Analysis is not committed to claiming that those who hold opposing views are conceptually confused, that their views are unintelligible or that they must be using different concepts. And conversely, the mere intelligibility of views that are inconsistent with the Locative Analysis does not entail its falsehood. The Locative Analysis will be incompatible with views that some people find plausible and it has to have something to say against these views, but the mere intelligibility of them is no objection to the analysis. Any analysis in ethics (of reason, value or morally wrong for example), as with analyses in other areas of philosophy, will be incompatible with intelligible views. This is the point established by Moore's Open-Question Argument.15 This is why mere intelligibility cannot suffice to undermine an analysis (and why it is better not to think of philosophical views as conceptual analyses). 16

Leaving aside these preliminary points, we need to know more about being "essentially related to X." ${ }_{17}$ My proposal is as follows: The relation of being essentially related to $\mathrm{X}$ holds between something $(\mathrm{G})$ and a subject $(\mathrm{X})$ if and only if the following conditions hold:

1. $G$ requires the existence of $X$ in order to be the case.

2. $G$ cannot persist in the absence of $X$.

3. G could not be the case without being X's.

Notice how pleasures meet these conditions. 18 Pleasures require particular agents to experience them and can neither predate nor outlast them

${ }^{14}$ Some have thought that we can give a buck-passing account of good for using something like clause (ii) alone. One such view is that to be good for someone just is to be something that has properties that generate, or would generate, agent-relative reasons for $\mathrm{X}$ to desire $\mathrm{G}$ for its own sake. However, such an account is too inclusive; it makes too many things good for $\mathrm{X}$. Unfortunately there is not space to discuss these views here. See Fletcher (2012).

15 Moore (1903).

16 For discussion of these issues see Schroeder (2007b, ch. 4) and Williamson (2007).

17 On the issue of the ownership of prudential goods, see Kagan (2009: 255-58).

18 This would be false if either (a) there is a deity that somehow feels our (e.g.) pleasures as we do, or (b) if certain theories in philosophy of mind and in personal identity turn 
(conditions 1 and 2). Suppose that we toss a coin to decide who gets to eat an apple; I win, I eat it and I get pleasure from doing so. Though there is an alternate course of events where you win the coin toss and pleasurably eat the apple, you do not experience the pleasure that I would have had; you experience only a similar one (condition 3).

Meeting these conditions is not peculiar to pleasure. Suppose arguendo that certain kinds of knowledge are good for people and that X has some such knowledge. This token of knowledge requires the existence of $\mathrm{X}$ in order to be the case and cannot persist in the absence of $\mathrm{X}$ (conditions 1 and 2). Suppose that $\mathrm{X}$ acquires this knowledge by reading a book and that if $\mathrm{X}$ had not read the book $\mathrm{Y}$ would have read it. It is still true that X's token of knowledge would not have been Y's, even if Y, rather than $\mathrm{X}$, had read the book and acquired knowledge of this subject matter (condition 3).

This has clarified the conditions for being essentially related and how they are met by at least these two candidates for prudential value. Something is essentially related to someone when these conditions are met and, if the other clauses of the Locative Analysis are satisfied, it is good for them.

So far, I have only explained the relation using single-subject goods, things that are essentially related to only one subject and good for them alone. But not all goods are like this. One clear example of this is friendship; the analysis must accommodate such multiple-subject goods. Multiplesubject goods such as friendship (F) are essentially related to more than one subject, $\mathrm{X}$ and $\mathrm{Y}$, and thus meet the requirements for being essentially related to each of them:

\footnotetext{
4. $\mathrm{F}$ requires the existence of $\mathrm{X}$ and $\mathrm{Y}$ in order to be the case.

5. $\mathrm{F}$ cannot persist in the absence of $\mathrm{X}$ and $\mathrm{Y}$.

6. F could not have been the case without being $\mathrm{X}$ and $\mathrm{Y}$ 's.
}

Multiple-subject goods such as friendships are essentially related to more than one subject. And if they satisfy the other conditions, they are good for every subject to whom they are essentially related.

This is how friendship meets these conditions: My friendship with $\mathrm{Y}$ could not have arisen in our absence and cannot outlast us (conditions 4 and 5). No one else could have, or could have had, our friendship (condition 6). Multi-subject goods, then, are essentially related to more than one subject and good for each. ${ }^{19}$

This makes the Locative Analysis clear by articulating the essentialrelation claim and showing that it works for both single-subject goods and multiple-subject goods. It is noteworthy that every plausible candidate for being part of well-being - pleasure, friendship, knowledge, happiness, virtue, health, achievement, self-respect, aesthetic appreciation -

out to be correct. Though these are interesting possibilities, I omit discussion of them here due to constraints of space.

19 This rules out the possibility of multi-subject goods being (non-instrumentally) good for one subject without also being good for the other. 
meets this condition. This is evidence that it is part of the correct analysis of good for.

Having articulated the Locative Analysis, I now outline some of the merits of the view in order to make clear why we should be interested in this view and in seeing how it can handle objections (which I do subsequently).

\section{The Merits of the Locative Analysis}

The Locative Analysis has a number of positive features that are worth pointing out. The first is that it gives an analysis of good for that is illuminating and noncircular. This is a significant merit of the view. By contrast, a major competitor of the Locative Analysis, Darwall's Rational Care Theory, has a worrying kind of circularity. Darwall's analysis is:

[W] hat it is for something to be good for someone is for it to be something that is rational (makes sense, is warranted or justified) to desire for him insofar as one cares about him. ${ }^{20}$

Because this analysis involves care, which involves (at least) a desire for the subject's well-being, the analysis is at least somewhat circular. The Locative Analysis has no such problem. We do not need to know what well-being is before we can understand the terms of the analysis. Nor does the analysis invoke prudential reasons, which would make it circular if we had no independent specification of these.

Second, the Locative Analysis can plausibly explain intuitions about the subject-relativity of prudential value. Philosophers have long remarked on the apparent subject-relativity of good for and have sought to accommodate this in different ways. One way has been to hold that something is good for someone if and only if she desires it. But this faces serious difficulties..$^{21}$ By contrast, the Locative Analysis can take this subject-relativity to be explained by two features of the analysis. First, that only something that has properties that generate, or would generate, agent-relative reasons to desire the thing can be good for them. Second, that only something that has the feature of being essentially related to the agent can be good for them.

Note that those who have attempted to refine theories of wellbeing have often incorporated elements that look to either track or be very similar to the relation of being essentially agent related.22 One such example is the experience requirement that some have sought to incorporate into first-order theories of well-being. ${ }^{23}$ Similarly, desire-fulfillment

\footnotetext{
${ }^{20}$ Darwall (2004: 9).

21 The main difficulty is the "Scope Problem," namely the fact that many of our desires are for things unconnected to our well-being. For discussion of this see Overvold (1980: 117-18, n. 10), Darwall (2004: 29-31) and Sobel (1998: 268).

22 I do not claim that there is no other possible rationale for these things, only that they give some support to the claim that something like the essentially agent-related feature guides our judgments about well-being (albeit implicitly).

${ }^{23}$ For discussion see Heathwood (2006) and Sumner (1996).
} 
theorists have sometimes refined their theories to incorporate elements that are similar to the essential agent-relation criterion. Overvold suggested that the desire-fulfillment theory restrict itself to those desires for states of affairs of which the agent is an essential constituent, ${ }^{24}$ and Portmore objects to the desire-fulfillment theory thus:

\begin{abstract}
Imagine, for instance, that Abe is a fan of large prime numbers and so wants the total number of atoms in the universe to be a prime. On the unrestricted desire theory, then, we would have to say that he is worse off if, in fact, the total number of atoms in the universe is not a prime. But this is absurd. How could something so remote from him possibly affect his welfare? It would seem that a theory of welfare must explain which facts constitute his being harmed or benefited, and so these facts must be facts about him. ${ }^{25}$
\end{abstract}

We can use the essentially agent-related criterion to explain Overvold's suggestion and Portmore's thought that things that can be good for an agent must have something to do with the agent. For something to be good for an agent it must be essentially related to them in a way that the number of atoms in the universe being prime is not.

Thus the second merit of the Locative Analysis is that its features such as the essentially agent-related criterion - cohere with and possibly explain this subject-relativity intuition. The analysis can also explain what some have found dissatisfying in some first-order theories of well-being and how others have tried to improve those theories.

A third positive feature of the Locative Analysis is that it yields a way to give a grounding for objective-list theories of well-being and to make progress in developing theories of well-being. Even those attracted to such theories appreciate that such theories can appear to be both an unconnected heap of goods and terribly ad hoc if no principled rationale can be given for the items on the list or their relative importance. The Locative Analysis suggests a way of answering each of these worries. First, it provides resources for ranking the goods on the list in terms of the elements of the analysis, namely the degree of value and the strength of the agent-relative reasons. Second, the analysis imposes informative conditions on what can be good for someone, namely only things that meet the conditions specified in the analysis. This suggests a way of narrowing down and determining what should be on the list. 26 Thus the Locative Analysis opens up new ways to go in theorizing about well-being.

Fourth, the Locative Analysis explains why good for is a normative property. ${ }^{27}$ The normativity of good for is explained by the fact that something's being good for someone involves its both being valuable and its generating agent-relative reasons to desire. Thus the normativity of good for is explained by its inheriting the normativity of value and of reasons.

24 Overvold (1980). See also Hooker (1998: 144) and Portmore (2007).

25 Portmore (2007: 28) (italics in original). The example and original discussion of this point comes from Kagan (1992: 37).

26 This is not to say that it is the only possible rationale - human nature perfectionism is another - only that it is a new one.

${ }^{27}$ See Darwall (2004: 10-11) for discussion of the normativity of welfare. 
This vindicates the idea that good for is normative - like wrong, good and ought - rather than non-normative. ${ }^{28}$

Having highlighted the merits of the Locative Analysis I now examine objections to it, some of which already appear in the literature. ${ }^{29}$ In the next two sections I address objections from Sumner.

\section{Sumner's First Two Objections to the Locative Analysis}

Sumner is one of the few writers who discusses the Locative Analysis and he provides a number of interesting challenges to it. His first objection is that, applied to persons, the Locative Analysis has counterintuitive results:

Suppose, as Moore himself once argued, that beauty belongs on the list [of intrinsic goods]. In that case, the theory entails that beautiful people are necessarily better off, at least in one respect, than plain or ugly ones. ${ }^{30}$

It may seem flatfooted to say so, but it is plausible that this is the correct result. As Sumner fairly points out, the claim is only that such beauty is good for the person to some degree. The theory is not committed to claiming that being beautiful is the only good thing for a person, or that it is greatly beneficial, or that it is beneficial overall (someone might be worse off overall for being beautiful through suffering due to the envy of others, for example). To see that this might be the correct result, consider the following scenario: You are choosing which of two lives you are to lead in a world where there are no other people (or other appreciative subjects) and know that the lives would be identical except that in one of them you would be ugly and in the other one you would be beautiful. It is plausible that you would have at least somewhat stronger prudential reasons to choose the life where you would be beautiful - that it would be enough to break a tie for example - even if it might not make a significant difference.

Sumner's second objection is that the analysis applies too generally:

[The Locative Analysis] will also entail that every beautiful object has its own welfare, since it will be true of each such object that an intrinsically valuable state is a state of it. This would be a spectacular failure of the test of generality; however vague the outer boundary of the class of welfare subjects may be, mountains and sunsets and string quartets do not belong even to its periphery. ${ }^{31}$

28 I discuss below $(\$ 6)$ the issue of whether it is a normatively significant property, whether it itself generates reasons.

${ }^{29}$ I do not evaluate alternatives to the Locative Analysis in this paper due to constraints of space.

30 Sumner (1996: 50). Sumner does also have a preliminary challenge: "The theory obviously owes us some formula for determining when such a state of the world is to count as a state of some assignable subject." The discussion of the previous section fulfills this, so I ignore this part of his case.

31 Ibid. 
I take Sumner's claim to be that talking of what is good for these things, or of their welfare, is so implausible that if the Locative Analysis were to imply this then the analysis is flawed.

Sumner's claim raises important issues for the Locative Analysis and for discussion of good for generally. For clearly we do talk about what is good for a wide range of things. We think that allowing too many people to hike a particular path is bad for the mountain, that pollution is bad for the Great Barrier Reef and that well-made instruments are good for a string quartet, for example. So even if the Locative Analysis did entail that things can be good or bad for them, it is far from clear that this is a cost of the view. In light of this point, I think that a better articulation of Sumner's objection is the following claim: The Locative Analysis cannot be right because it cannot apply to our use of "good for" in these cases. ${ }^{32}$

Given that these kinds of claims using "good for" are commonplace, it would be a major selling point of a theory if it could solve this "Multiplicity Problem" by giving a unified treatment of our use of "good for" across all subjects.33 Unfortunately such a unified treatment of "good for" talk is not possible, as I shall explain shortly. ${ }^{34}$ "Thus I do not claim that the Locative Analysis is the correct analysis of "good for" talk across all of these cases. But on what ground can we distinguish cases in which the Locative Analysis applies from those to which it does not? Before giving my answer, I will briefly examine two proposed unified treatments of "good for" talk. Richard Kraut suggests the first thus:

\begin{abstract}
Living things are not the only things for which some things are good and other things bad. Some things are good for a car, other things bad. But truths about what is good for a car depend on truths about the ways in which they serve the good of human beings... So we can say: everything that is good for $\mathrm{S}$, whether $\mathrm{S}$ is living or not, either promotes or is part of flourishing. What is good for an artifact like a car is what promotes flourishing - not the flourishing of the car, of course (since there is no such thing), but the flourishing of buman beings... By contrast, what is good for a living being, as opposed to an artifact, is what promotes or is part of the flourishing of that same living thing. 35
\end{abstract}

On Kraut's view there is only one good for relation. 36 So "good for" used when talking about human welfare refers to the same relation as "good for" when talking about watches and pianos. This is an attractive feature of his account.

\footnotetext{
32 I owe this objection to discussions by Kraut (2007: 3) and Schroeder (2007a: 273, n. 19).

33 See Rosati (2009a) for the naming and extensive discussion of this problem.

${ }^{34}$ For clarity this is more categorical than the real conclusion, which is: If certain assumptions are not met (and they look not to be), one cannot give a unified treatment. ${ }^{35}$ Kraut (2007: 132) (my italics)

36 That is, the relation of promoting flourishing, though there are differences as to whether it is the flourishing of the thing itself (as in humans and animals) or something else (as in the case of artifacts). But see Rosati (2009a: 212) for doubts about whether Kraut consistently defends a single good for relation.
} 
Unfortunately Kraut's proposal has implausible consequences. ${ }^{37}$ Suppose that smashing up a car with a bat will provide stress release that cures a chronic, long-lasting migraine (or other serious condition) of X's. It would be good for X to smash up the car. But it would not be good for the car, as Kraut's view suggests, and this kind of problem is general so we cannot draw the distinction the way Kraut does.

Look again at the types of example we have in mind here: sharpening is good for knives; cholesterol is bad for hearts; sugar is bad for gas tanks; sand is bad for watches; rain is good for trees; air pollution is bad for the ozone layer; flash photography is bad for oil paintings; acid rain is bad for rainforests; new strings and practice are good for string quartets. Notice that these subjects can have attributive goodness, or goodness of a kind, and what is good or bad for them seems obviously related to their attributive goodness. The following look like extremely plausible analyses of what it is for something to be good for and bad for such subjects (which I will call "non-welfare subjects"):

Good for (non-welfare subjects): What is good for an X is that which is a (productive or constituent) means to its becoming, or remaining, an attributively good X.

Bad for (non-welfare subjects): What is bad for an $\mathrm{X}$ is that which is a (productive or constituent) means to its being a less attributively good $\mathrm{X}$ or ceasing to be an attributively good X. 38

These analyses get the right answers in these cases. To be good for a string quartet just is to be something that contributes towards making it, or preserving it, as a good (or better) string quartet. And to be bad for a sunset just is to be something that in some way contributes towards making it a bad (or worse) sunset. And this same analysis works for all of the cases mentioned above, such as gas tanks, bicycles, watches, etc. The second proposed unified treatment of "good for" would be to extend this kind of analysis to all uses of "good for" and "bad for," including their application to humans and other animals.

Unfortunately this second unified proposal will not work. While it is true that to be good for an artwork just is to be conducive to its becoming or remaining a good artwork, the relation of being good for a person is not that of being conducive to their becoming or remaining a good person. Pleasure might be good for me without making me any more (or less) virtuous, for example, and the same goes for other welfare subjects. It is clear that some things are good or bad for gorillas but these things do not seem to be that which conduces to making them good gorillas, whatever

\footnotetext{
${ }^{37}$ Rosati (2009a) also suggests a number of problems for Kraut's view. For discussion of Kraut's view generally see Fletcher (2009).

38 Actually, Kraut (2007: 3) outlines a similar account thus: "Whatever enhances the performance of an artifact or its ability to play its role is good for it; whatever damages it or detracts from its suitability to achieve its purpose is bad for it." The connection between his two accounts is left unstated, presumably because he thinks that they are equivalent because the (ultimate) function of an artifact is always to promote flourishing.
} 
that might be. Thus this new unified proposal - that of treating all "good for" talk as connected to attributive goodness - will not work.

From the failure of this second unified analysis we can find a way for the Locative Analysis to avoid Sumner's second objection. This objection, in its amended form, was that the Locative Analysis is an implausible analysis of "good for" as applied to subjects such as string quartets, mountains, pianos, watches, etc. We have seen that the correct analysis of "good for" for these cases cannot be extended to humans and animals. Thus our good for talk in these cases is legitimately distinguished from "good for" talk in the case of humans and animals. Thus the holder of the Locative Analysis has a rationale for limiting their view and preventing it from applying too widely, to things such as string quartets, watches and pianos. They can hold that the Locative Analysis does not apply to "good for" and "bad for" talk in these cases because these cases can all be understood in terms of attributive goodness, but this analysis just is not plausible in the cases to which the Locative Analysis applies, namely humans and other welfare subjects.

This distinction prevents the Locative Analysis from applying too widely (such as to string quartets) and it is also plausible. Our judgments about which things are good and bad for other subjects - such as pianos, gas tanks and watches - are always implicitly, sometimes explicitly, with reference to their attributive goodness in a way that our judgments about what is good or bad for humans are not. And while we talk about what is good and bad for (e.g.) hammers, we do not talk about how well off they are. And we do not think that they have a level of well-being, nor do we ask how well things are going for them. ${ }^{39}$ All of this adds to the plausibility of taking "good for" as applied to humans and animals as being different from its application to other subjects. Thus the Locative Analysis gets the right result - it does not apply to gas tanks, pianos and string quartets - and has a plausible and principled rationale for this, namely the difference between "good for" talk as applied to humans and animals and to other subjects. 40

\section{Sumner's Third Objection to the Locative Analysis}

I move on to Sumner's third objection to the Locative Analysis. This objection concerns the order of explanation it countenances. He writes:

\footnotetext{
39 This invites the question of whether the distinction is simply one between (a) living things and (b) nonliving things. But while this distinction looks to get many of the right results, there are certain problematic cases and difficult issues for it - such as fungi, viruses, plants and bacteria - to borrow some examples mentioned by Rosati (2009a: 224). For this reason, I stick with the above distinction.

40 As Rosati (2009a: 208) points out, Sumner also needs to make a distinction like this one, given that his view of welfare cannot be plausibly applied to artifacts. Rosati (2009a: 209) also suggests that the same point applies to Darwall's Rational Care Theory. Though I am sympathetic to this, it is perhaps less clearly a problem for Darwall's theory than for Sumner's. For it is less obvious that we cannot care for (e.g.) artifacts, as Darwall's view requires, than that they cannot have authentic happiness!
} 
What is odd about the private ownership theory [Sumner's term for the Locative Analysis] is the order of explanation to which it is committed. The theory tells us that prudential value depends on ethical value: certain considerations make our lives go better because we have a moral reason to bring them about...Suppose we are wondering whether deep personal relationships have any prudential value. The theory reaches an affirmative answer to the question by first establishing that these relationships have ethical value, and then concluding that they must therefore make our lives go better. ${ }^{41}$

There are a number of understandable but problematic assumptions in this passage, perhaps stemming from Sumner's discussing the view in the context of Moore's wider theory. The first is Sumner's talk of "ethical value." We should omit this. Claims about ethical value are no part of the Locative Analysis, which is couched in terms of value simpliciter. Second, the Locative Analysis is silent on the connection between value and reasons, especially moral reasons to bring things about, for this is a separate issue. If we omit these, we are left with not an objection per se but a statement of the view. The holder of the Locative Analysis can argue that it is plausible to think that the goodness of things partly explains their being good for us (and not vice versa). When we think prudentially we are attempting to locate and pursue things that are good (or that we take to be good) and to secure them for ourselves. And when we reflect on what we want for loved ones it is commonplace to think that we want them to have good things and to avoid bad things. ${ }^{42}$ Sumner's objection, in its pared-down form, reveals nothing implausible about the analysis.

This is not an idiosyncratic claim about value, made simply in order to defend the Locative Analysis. Dancy, Raz and Scanlon make similar claims:

The reason why things make one's life go better is that they are fun, rewarding, engrossing and so on, worth doing in their own right. It is not the other way around. Perhaps better: that something is fun, or in some other way worth doing, is not a reason to do it because one has a general reason to make one's life go better, and having fun is one way of doing that (sometimes). That this would be fun is its own reason to do it, and one's life goes better to the extent that one is able to do a wide variety of the things that one has good reason to do.43

Only valuable activities contribute to our well-being. A life is not a good for life for being spent in petty vindictive pursuits, or in self-debasing ones, etc. These make it a lousy, despicable, pitiable life - not a good one. ${ }^{44}$

It would make sense to say that I work hard at philosophy because I believe it is worthwhile, or because I enjoy it, or even because I long for the

\footnotetext{
${ }^{41}$ Sumner (1996: 51).

${ }^{42}$ For a similar response to Sumner, see Brewer (2009: 211-13).

43 Dancy (2007a: 86). One complication here is the question of what could fall under the "and so on." Someone might argue that this could include something's being good for someone, in which case this passage does not support the explanatory relationship that I defend. But I doubt that this is the intended meaning.

${ }^{44} \operatorname{Raz}$ (1995: 4).
} 
thrill of success. But these things in turn are not desirable because they make my life better. Enjoyments, success in one's main aims, and substantive goods such as friendship all contribute to well-being, but this idea of well-being plays little role in explaining why they are good. This might be put by saying that well-being is what is sometimes called an "inclusive good" - one that is made up of other things that are good in their own right, not made good by their contributions to it. ${ }^{45}$

This is not an appeal to authority. It is intended only to establish that the Locative Analysis is not idiosyncratic in taking things to be good for a subject (at least in part) because they are good. And for the reasons noted above, this also seems a plausible result.46, 47

To conclude the response to this objection, it is worth noting two claims that do not follow from the explanatory relationship postulated by the Locative Analysis but which are quite similar to Sumner's claim and might be confused with it.

First, the Locative Analysis does not entail that the fact that something is good for you is not a reason to choose it. The holder of the Locative Analysis can say that among the reasons to choose or promote something is the fact that it is good for you. Even though clause (ii) of the analysis makes reference to pro-attitudes, as explicitly pointed out earlier, this clause does not include all pro-attitudes. Thus there would be no difficulty for the analysis in someone's judging that, in at least some cases, the fact that something would be good for someone is a reason to choose it.

Second, one could coherently combine the analysis with the claim that someone being benefited is itself good. That is to say, even if (as the analysis says) some pleasure's being good for someone is partly explained by its being generally good, one can also hold that someone's getting something that is good for them is a further (higher-order) good. The analysis does not commit one either way on either this issue or the previous one.

\section{Regan's Objection to the Locative Analysis}

Sumner's third objection is similar to one presented against the Locative Analysis by Donald Regan. Regan's objection is part of a dilemma that he constructs for what he calls "good for theorists," namely those who take good for to be significant. The dilemma stems, roughly, from the thought that to adopt the Locative Analysis would be to give up on good for in

45 Scanlon (1998: 127).

46 This does not commit the Locative Analysis either to holding, or denying, a buckpassing analysis of goodness. The theory is neutral on that (separate) issue. All I am committed to claiming is that something's being good (whatever the nature of that turns out to be) explains its being good for someone. It is true that the analysis suggests that, if the non-instrumentally good somehow entails agent-neutral reasons to favor, then agents have, or can have, both agent-relative and agent-neutral reasons to favor that which is good for them.

${ }^{47}$ Because of this explanatory relationship the Locative Analysis is well placed to accommodate Scanlon's (1998: 142) claims that well-being is not a "master value" but an inclusive good. 
some sense (clarified below). I focus here on the first horn of the dilemma - the only one directed against the Locative Analysis. ${ }^{48}$ The conclusion of Regan's dilemma is that:

[W] ell-being [which Regan takes as synonymous with good for, prudential value, etc.] as a normative concept does not figure in the best account of why we are obligated to care about what happens in others' lives (or, for that matter, in our own). ${ }^{49}$

Regan's case against the Locative Analysis is that no "good for theorist" can accept that "good for" should be analyzed as "good and occurring in the life of" because such an analysis "would amount to abandoning 'good for' as an independent concept." ${ }_{50}$

Horn one: If we explicate the "for" in "good for X" in an empirical way then we give up "good for" as an independent concept. ${ }^{51}$

This might be read as the claim that if "good and in the life of" were our analysis of good for then it would not be basic because it would incorporate good. But this is not Regan's real charge, for there is no problem for the Locative Analysis in good for not being an independent property, just as it would be no objection to an analysis of bachelor that it shows bachelorhood to be composed of other properties. Regan's objection is, rather, that if the Locative Analysis were true this would mean that good for is not normatively significant, that it would not play a role in the explanation of our reasons for action. This interpretation is suggested by Regan's overall conclusion that good for: "does not figure in the best account of why we are obligated to care about what happens in others' lives (or, for that matter, in our own)." ${ }_{52}$

So, Regan takes his first horn to show that the good for theorist cannot relativize the goodness in good for in what he terms a "purely empirical way," as in the Locative Analysis, because we could then give up on good for and just use good because it would be the latter that does all the normative work. 53

But this is too quick and the Locative Analysis has a reply. Pace Regan, whether good for can do any normative work is left open by the analy-

48 For extensive discussion of Regan's argument generally see Rosati (2008) who finds Regan's argument wanting on some grounds that are similar to those developed here.

49 Regan (2004: 203).

${ }^{50}$ Regan calls the Locative Analysis the "Moorean Analysis" in his discussion. To avoid confusion, I stick with the "Locative Analysis" but, for clarity, I preserve Regan's "in the life of' rendering.

${ }^{51}$ For continuity, I translate Regan's concept-talk into property-talk (quotations aside). 52 Regan (2004: 203). Similarly, Regan (2004: 213) writes: "Instead of saying first that a certain state is Good for Abel, and then that Abel's having what is Good for him is Good simpliciter, why not just say that the state in question is Good simpliciter? It is not clear that the reference to 'Good for' is doing anything significant." Though he is attacking a different, hybrid, view of good for when he makes this charge, I take it to be an expression of the same point - that the view makes good for do no normative work.

53 By "empirical," Regan means the "non-normative" or "descriptive." 
sis. Absent some of Regan's understandable but contentious assumptions, his conclusion need not follow. I will now explain why.

Regan (presumably because of his Consequentialism) assumes that all reasons stem from, or are explained by, goodness alone and this is why there would be nothing for the rest of the analysis to do to determine the reasons that subjects have. But this is a contentious assumption and without it there is no trouble in seeing how normative work could be done by good for. That something would be good and in the life of $X$ could make a difference to the reasons that agents have, such as by making the reasons that they have to bring it about stronger than their reasons to bring about equivalent goods for others. Suppose that A can bring about some good $(G)$ for their child, X, or something equally good for a distant stranger, $Y$. The fact that $G$ would be good and in the life of $X$ can make a difference to the reasons that $\mathrm{A}$ has, such as making it the case that $\mathrm{A}$ has more reason to bring about this good for $\mathrm{X}$ than an equivalent good for $\mathrm{Y}$. This is just one way that good for could do normative work. ${ }^{54}$

Thus Regan's claim - that if the Locative Analysis were true there would be no normative work for good for to do - only follows if we assume that facts about goodness alone explain the reasons that agents have. But this is contentious, to say the least, and in the absence of a good reason to believe it we can say that good for can still do normative work even if we relativize good for in what Regan calls an "empirical way." So Regan has not yet shown that the Locative Analysis prevents good for from doing any normative work..$^{55}$

There is another, more concessive, response that the Locative Analysis can make. This is that even if Regan were right that the Locative Analysis prevents good for from being normatively significant, this is no objection to the analysis. The analysis might still be correct about what good for is, it is just that this is a normative property that does not itself generate reasons or requirements. But this is no shortfall of the analysis.

There is a parallel here with analyses of goodness and wrongness. Those who hold buck-passing analyses of these properties think that (e.g.) the fact that an action is wrong is not itself a reason not to perform the action, it is rather the property of the balance of reasons being against the action. This does not preclude wrongness from being a normative property and the fact that this is a normative property that does not itself do any normative work is unproblematic. The more concessive response to Regan is to say the same about good for. Even if the Locative Analysis meant that good for turned out not to be normatively significant (because it does not itself generate reasons) this does not prevent the Locative Analysis from being a good analysis of good for, just as buck-passing analyses of good and wrong can be correct and have this feature.

My twofold response to Regan's dilemma is thus as follows. First, Regan has not shown that relativizing good for in an empirical fashion pre-

\footnotetext{
54 My claim is not that it would be part of what it is for $\mathrm{G}$ to be good for $\mathrm{X}$ that it would generate these partial reasons for A to bring about this thing for X. Rather, these reasons are implications that follow from the fact that it would be good for X.

55 On this point see also Rosati (2008: 328).
} 
vents good for from figuring in the best account of why we are obligated to care about what happens in the lives of others and ourselves. For though this would follow if we assume that goodness alone determines all of the reasons we have, we need to be given a convincing case for that claim. Thus it is still possible that the other parts of the analysis can do normative work in determining the reasons that we have and so something's being good for $\mathrm{X}$ can make a difference to the reasons that agents have (over and above the fact that the thing is simply good). ${ }^{56}$ Second, even if Regan were right that the Locative Analysis makes good for normatively insignificant this would not prevent it from being a good analysis of good for. Though I happen to think that good for does normative work, this is not a condition of adequacy for an analysis of it and the Locative Analysis still retains all of its merits if it shows good for to be a normative property, even if it shows it to be a property that does not itself generate reasons. ${ }^{57}$

\section{Good For but Not Good?}

I move on now to consider another likely objection, starting from a suggestion by Mark Schroeder. I argued above that it is no problem for the Locative Analysis that it claims that something is good for someone because it is good. But someone might make a different charge. They might claim that, rather than the order of explanation between good and good for being incorrect, the Locative Analysis is mistaken because good and good for diverge in a way that falsifies it. Schroeder mentions a case that might be thought to make trouble for the Locative Analysis in this fashion. He writes:

A tax policy can be good for Dick Cheney's pals without being good[.] $]^{58}$

Suppose the tax policy is one in which everyone pays a tax to Cheney and his pals at a rate inversely proportional to income. Clearly this is not good, but it could be good for Cheney's pals. Can the Locative Analysis say this? Thankfully it can.

First, note that the tax policy is only instrumentally good for Cheney's pals. It is a means to things that are non-instrumentally good for them; it is not itself non-instrumentally good for them. Thus to avoid this problem case we need to remember that the Locative Analysis is an analysis of what is non-instrumentally good for subjects, for then Cheney's pals' tax policy is not a counterexample. It is no objection to the analysis that something instrumentally good for someone need not be good. The Locative Analysis only claims that if something is non-instrumentally good for someone then it must be good.

A similar response can be used to handle a different case. Consider a Venus Flytrap eating a fly. It is plausible that this is good for the Flytrap

56 I have not given an argument here for the claim that good for does normative work. But this is too big an issue to try and settle here.

${ }^{57}$ For critical discussion of Regan's argument see also Arneson (2010: 738-39).

58 Schroeder (2007a: 272). 
(and bad for the fly) but it does not seem plausible to say that this is good simpliciter. ${ }^{9}$ Nonetheless, this is no problem for the Locative Analysis. This is because eating the fly is only instrumentally good for the plant. So this is no counterexample to the Locative Analysis.60

Someone might grant this about the Cheney and Flytrap cases but point to a different example. For instance, Feldman perhaps suggests that bad things can be non-instrumentally good for a subject. ${ }^{61} \mathrm{He}$ describes a case in which a child-hating terrorist sets off a bomb in a playground, watches the ensuing carnage and experiences great pleasure:

\begin{abstract}
When we consider a case such as this, it is essential that we keep in mind the fact that we are talking about evaluation of the life in itself, for the one who lives it. We are not asking whether the terrorist led a morally good life, or whether he led a life that was good for others. Nor are we asking whether his pleasures were admirable. We are asking whether he led a life that was good in itself for him...Perhaps the life of the terrorist, though disgraceful and morally indefensible, was not so terribly bad in itself for him. ${ }^{62}$
\end{abstract}

This cannot be handled like the tax case. I will instead highlight two different ways one could defend the Locative Analysis in order to show that this is a place where even those who hold the Locative Analysis can diverge.

The first option would be to deny that something that is bad or neutral could be (non-instrumentally) good for someone.63 Other writers make such a claim and holding it need not be a matter of biting bullets. ${ }^{64}$ For example, it could be that such pleasure is an expression of a damaged or depraved character and that such expression cannot be good for a person. Foot puts a similar claim as follows:

For suppose that we think of some really wicked persons such as the serial killers Frederick and Rosemary West, who did not even spare their own children in their career of abuse and murder. For many years they were able to act out their sexual fantasies free from detection, and might well have continued to do so to the end of their natural lives. What then would it have been right to say about the contribution of those whose behavior made this kind of thing possible? Would they have benefited the horrible Wests? It seems to me that in our natural refusal to say so we glimpse a conceptual truth that does not usually lie so clearly on the surface. And that if the usual conceptual connections hold here, as they surely do, be-

\footnotetext{
${ }^{59}$ I thank an anonymous referee for suggesting this case.

${ }^{60}$ But is the event non-instrumentally bad for the fly? It depends on whether it involves pain and whether death, itself, is non-instrumentally bad for the subject. If so, then it is plausible that the event is, itself, non-instrumentally bad. I am here accepting that the fly and flytrap are welfare subjects only for the sake of argument.

${ }^{61}$ The "perhaps" is because the "perhaps" at the beginning of his final sentence makes Feldman's position unclear. I will assume that this is his position but nothing hangs on this.

${ }^{62}$ Feldman (2004: 39).

${ }^{63}$ For brevity, I omit the "non-instrumentally" in what follows.

${ }^{64}$ See the above passages from Dancy, Raz and Scanlon.
} 
tween benefit and what is for someone's good, what has come to the surface is also about that. ${ }^{65}$

Though Foot's point concerns the activities of those who made the depraved activities of the Wests possible, I take her claim to apply also to the activities themselves: They were not good for these people and these kinds of lives are not good for those who live them. Similarly, Adams writes:

I doubt that enjoyment of what is not in any way or degree excellent can be a constituent of our good; surely it cannot at any rate be an important constituent of our well-being. [Concerning instances of schadenfreude]... These seem to me not to contribute noninstrumentally to our good at all; one reason that they do not may be that the enjoyments themselves are bad in a way that diminishes the excellence of our lives. ${ }^{66}$

A reluctance to think that such activities, even if enjoyed, are good for those who engage in them, coupled with the ability of the Locative Analysis to provide an explanation for this, gives support to the Locative Analysis' claim that only good things can be good for someone, against the Feldman position.

However, because the question of whether something that is bad can be good for someone is a contentious, substantive issue - as evidenced by distinguished philosophers appearing on both sides - I will not try to settle it here. Thankfully, I do not need to. This is in part because I have already shown that the Locative Analysis being committed to this explanatory relation is not a decisive counterexample to it. More importantly, though, there is a second reply to these kinds of cases, which is more concessive to those who think that something bad could be good for someone. Because part of the aim of this paper is to present and point out some of the features of such an analysis, it is more useful to explain this alternative option rather than pursuing the task of sustaining the first strategy.

The second way to handle putative cases of something bad that is good for someone would be to move from the analysis as originally formulated:

Locative Analysis: G is non-instrumentally good for X if and only if (i) $\mathrm{G}$ is non-instrumentally good, (ii) $G$ has properties that generate, or would generate, agent-relative reasons for $\mathrm{X}$ to desire $\mathrm{G}$ for its own sake, (iii) $\mathrm{G}$ is essentially related to $\mathrm{X}$.

- to a less demanding one, one that simply requires that the thing be pro tanto good, or good in some respect:

Weaker Locative Analysis: G is non-instrumentally good for X if and only if (i) $\mathrm{G}$ is pro tanto non-instrumentally good, (ii) $G$ has properties that generate,

${ }^{65}$ Foot (2000: 94).

66 Adams (2002: 100-1). See also Brewer (2009: 216-18). 
or would generate, agent-relative reasons for $\mathrm{X}$ to desire $\mathrm{G}$ for its own sake, (iii) $G$ is essentially related to X. ${ }^{67}$

This weaker analysis can handle the case introduced above. For I assume that those who think that bad things can be good for people hold that there is something pro tanto good about such pleasures. Assuming that this is so, there is a form of the Locative Analysis that can accommodate these cases and give the result that Feldman suggests. The only types of cases that it could not accommodate would be ones in which something is good for someone without this being explained by its being even pro tanto good. It is not easy to think of a plausible contender for such a thing nor do there seem to be examples in the literature. For that reason, I do not think that such cases would be problematic counterexamples to the Locative Analysis in this weakened form.

As mentioned above, because my aim in this paper is to explain and defend the Locative Analysis in general, I have suggested two possible strategies in reply to the type of case discussed in this section and I have not defended one strategy in particular. Nonetheless, this suffices to show that the Locative Analysis can respond to purported cases of things that are not good but are good for someone.

\section{Good but not Good For?}

Having replied to objections involving purported instances of things that are good for someone but not good, I now turn to three cases that might be thought to exhibit the opposite kind of problem for the Locative Analysis: things that are good but which are not good for the relevant agent. The first is punishment; the second is virtue and self-sacrifice; the third is agent-centered duties.

The Locative Analysis might be thought to get into difficulties if combined with a certain view of punishment, one that I will call "value retributivism." This view claims that rather than punishment being justified instrumentally, through the value of its further consequences, such as deterrence, punishment is justified by the non-instrumental good involved in punishing a guilty person. This is because although punishment is itself bad, the combination of someone being guilty and being appropriately punished is a non-instrumental good, one which outweighs the disvalue of the punishment. 68

\footnotetext{
${ }^{67}$ Something is good in some respect if it has some element that is good, even if it is bad overall. Adopting the weaker analysis might require being more fine grained about what exactly the beneficial things are. For if something is pro tanto good in one respect and pro tanto bad in another (and meets the other conditions of the analysis) then the weaker analysis delivers the verdict that this is both good for and bad for the subject. The two ways to avoid this are to (a) change the Locative Analysis to a theory of pro tanto good for or (b) be more specific about what the beneficial thing is.

68 One could think of the view as claiming that the punishment that is inflicted is, itself, good. But this seems less plausible than the view that though the punishment is bad, the combination of crime-and-its-punishment is good as a whole, which means that things on the whole are slightly improved by punishing. For discussion of this, and value retributivism, see for example Hurka (1998) and Dancy (2007b).
} 
Someone might use this theory of punishment to launch an objection to the Locative Analysis as follows:

The combination of crime and its punishment would involve a noninstrumental good (and one that outweighs the non-instrumental bad of the punishment inflicted) and would be essentially related to the agent, thus it would fit the conditions of the Locative Analysis and thereby deliver the implausible verdict that such punishment, or such a combination of crime and punishment, is good for the person punished. ${ }^{69}$

Because I agree that it would be implausible to hold that such punishment is good for the person, I accept that the Locative Analysis needs to find a way to avoid this implication. Thankfully it can do so. Notice that for the objection to work it must also be the case that clause (ii) of the analysis is satisfied, that the agent has agent-relative reasons to desire this non-instrumental good. But the Locative Analysis has a plausible reply here, namely that however plausible the value-retributivist view is, ${ }^{70}$ it is considerably less plausible that the agent who would be punished would have agent-relative reasons to desire this state (their being punished for their crime). Even if the value-retributivist view of punishment were true, there are no good grounds for thinking that clause (ii) of the Locative Analysis would also be satisfied by punishment. Thus the analysis avoids this problematic implication of making punishment good for the person punished.

Having discussed the punishment example, I turn now to the objection that the Locative Analysis goes awry when it comes to virtue. This runs thus:

Doesn't the Locative Analysis get the wrong result in cases of virtuous people, like Mother Theresa? She did many good things in her life but her virtue and virtuous acts were not good for her. Furthermore, if you claim that virtue was good for her aren't you preventing the possibility of self-sacrifice and distorting what looks like self-sacrificing generosity? ${ }^{71}$

My response to this is that the Locative Analysis can coherently hold that virtue is good for someone and do so without either making self-sacrifice impossible or distorting the psychology of the virtuous agent. ${ }^{72}$ There are a number of claims that might mistakenly be thought to follow from claiming that virtue is good for the virtuous person. Once we see that

${ }^{69}$ Kagan (1992: 185) presses this case against a similar view to the Locative Analysis.

70 One thing to bear in mind when thinking about the value-retributivist view is that we need to decide what kinds of punishment could be non-instrumentally good. Some will think that none can; others will think that some could but that these will be very different from the punishments currently meted out by penal systems.

${ }^{71}$ Such a result - that it makes self-sacrifice or virtue impossible - is a recurrent theme in discussions of theories of good for. Indeed, it is a fixed point in our discussion of such theories that they not make self-sacrifice impossible. The most influential discussion of this kind of problem, discussed within the context of desire-fulfillment theories in particular, is Overvold (1980). For discussion of these issues see also Rosati (2009b).

72 It might be worth stressing that I mean that virtue can be non-instrumentally good for its possessor. That the virtues can be instrumentally good for their possessor is uncontroversial. 
these claims are separate from the Locative Analysis, the objection falls away.

Taking the case of Mother Theresa, someone who held the Locative Analysis could argue as follows. Insofar as her life contains the good of virtue it was good for her. But her virtue was only one thing that was good for her and acting virtuously made her worse off overall, through the loss of other good things that her virtuous actions deprived her of. Unless we also hold the entirely separate Platonic view - which is (roughly) that any degree of virtue is better for a person than any amount of other goods and outweighs any amount of bad - there is no problem in explaining how Mother Theresa acted self-sacrificially by being virtuous. Even if in acting virtuously there is a good for the person, a person can still be worse off overall for having virtues and for performing virtuous acts. Kraut highlights the difference between the Platonic view and this view when he writes:

Plato wants to show that justice is the greatest good one can have, but we are not asking whether the virtues are so much better than everything else that it is worth having them, even if one thereby loses everything else. There is a much simpler question that should be asked: is being a good person good at all for the person who is good? Or is being a good person a total loss from the standpoint of one's own well-being?73

Someone who held the Locative Analysis could allow that virtue is good for its possessor without making self-sacrifice impossible, as long as they retain two plausible claims. First, that it is not true that any degree of virtue or virtuous activity can compensate for any loss or absence of other goods or bads. ${ }^{74}$ Second, that self-sacrifice does not require someone to bring about only bad things for themselves; it merely requires someone to bring about less good for themselves overall. These claims are independently plausible and the Locative Analysis is compatible with them. ${ }^{75}$

Having removed two sources of mistaken opposition to the Locative Analysis and its treatment of virtue, I move on to addressing the last part of the objection. This is that if we hold that virtue is good for its possessor then we would distort the moral psychology of the virtuous agent, because when virtuous people act virtuously towards others they will in fact be acting for their own good, but the kind person acts for the sake of others, not for themselves.

This argument is a non sequitur. The kind person will not think of her action as one that is good for herself, nor will she perform acts because they are so. This is because what it is for someone to possess the relevant virtue is partly a matter of how they would represent the action,

${ }^{73}$ Kraut (2007: 192). Compare Socrates in Apology (41d): "[A] good man cannot be harmed either in life or death.” For discussion, see Plato, The Republic (Book 10: Part 11) and, for example, Bobonich (2002).

${ }^{74}$ But for sympathetic treatments of this kind of view see: Aristotle, Nicomachean Ethics (1168b-1169b), Brewer (2009: 203-4) and McDowell (1980: 368-70).

75 Anyone who includes virtue in their account of well-being has to hold these claims in order to avoid the charge of making self-sacrifice impossible. For discussion of these issues see Brewer (2009: 203-4); Hooker (1998); Plato, The Republic, and Raz (2000). 
and the reasons for which they would perform it. If people were to do good deeds for strangers because in doing so they would be acting kindly, and would benefit themselves because the virtue of kindness is good for its possessor, then they lack a correct understanding of what kindness is, and they lack the virtue. Holding that virtue is good for its possessor does not thereby direct the virtuous person's attention towards their own good; and this is because part of someone's having the relevant virtue is their attention being drawn towards others and away from themselves. Thus there is no plausibility in claiming that holding virtue to be good for its possessor distorts the moral psychology of the virtuous agent.

I have attempted to undermine the threat from the objection to the Locative Analysis based on virtue being good for someone. I have shown that the troubles stem from theses to which the analysis is not committed (and which are independently implausible). Thus there is no counterexample to the Locative Analysis from the fact that it can be committed to the claim that virtue is good for its possessor.

The third, and final, objection of this form I will consider is the claim that the Locative Analysis implausibly delivers the result that agentcentered duties are good for the agent. ${ }^{76}$ Take X's duty to look after X's own children. Someone might argue that this duty meets each of the conditions of the Locative Analysis and thus implies that such a duty is good for the agent. I think that such a charge is mistaken for the following reason: Agent-centered duties perhaps meet the third clause - they are essentially related to $\mathrm{X}$ - but they fail to meet clauses (i) and (ii). Agent-centered duties are not themselves non-instrumentally good. Of course they are correlated with things like friendship and other relationships (for example). But they do not themselves possess noninstrumental value. Thus they do not meet clause (i) of the analysis. And while an agent might have agent-relative reasons to adopt pro-attitudes towards upholding their agent-centered duties it seems doubtful that the duties themselves have properties that generate agent-relative reasons for pro-attitudes from the agent. Thus they do not meet clause (ii) of the Locative Analysis either. Thus agent-centered duties do not pose trouble for the Locative Analysis.

\section{Conclusion}

Herein I formulated, motivated and defended the Locative Analysis of good for. In its final (stronger) form, this analysis is as follows:

Locative Analysis: $\mathrm{G}$ is non-instrumentally good for $\mathrm{X}$ if and only if (i) $\mathrm{G}$ is non-instrumentally good, (ii) $G$ has properties that generate, or would generate, agent-relative reasons for $\mathrm{X}$ to desire $\mathrm{G}$ for its own sake, (iii) $\mathrm{G}$ is essentially related to $\mathrm{X}$.

\footnotetext{
${ }^{76} \mathrm{I}$ thank an anonymous referee for pressing me to discuss this example.
} 
I also presented an account of when something, $G$, is essentially related to a subject $\mathrm{X}$. This required that the following conditions be met:

1. $G$ requires the existence of $X$ in order to be the case.

2. $G$ cannot persist in the absence of $X$.

3. G could not be the case without being X's.

The merits of the analysis include the following. First, it provides a genuinely informative analysis of good for and thereby avoids the problems that afflict competing views, such as Darwall's. Second, the analysis (specifically its second and third clauses) explains widespread intuitions about the subject-relativity of good for and why people have responded to and developed theories of well-being in the ways that they have. These include the scope-problem objection to desire-fulfillment theories and the fact that some have wished to incorporate an experience requirement into theories of well-being. Third, the analysis provides a way to justify and to develop first-order theories of well-being. Fourth, the analysis explains and justifies the claim that good for is normative.

In addition to presenting and motivating the Locative Analysis, I examined a number of objections from, or inspired by, the works of Sumner, Regan, Schroeder and Feldman. I also preempted an objection that the analysis gives the wrong results concerning punishment and virtue. This is not an exbaustive list of the objections that one might press against the analysis. But I have shown that the Locative Analysis does not fall to these objections.

In this paper I have shown how the Locative Analysis should be formulated; that it has a number of theoretical virtues; and that it has plausible replies to the standard objections to it. It is worth taking seriously as a contender for the correct analysis of good for. ${ }^{77}$

Guy Fletcher

University of Edinburgh

Department of Philosophy

Guy.fletcher@ed.ac.uk

\footnotetext{
77 A veritable army has helped me with this paper. For comments or discussion of these issues I should thank: anonymous referees, audience members at BSET, Steve Campbell, Alex Gregory, Daniel Halliday, Ulrike Heuer, Richard Kraut, Seth Mayer, Francesco Orsi, Connie Rosati, Alex Sarch, Nic Southwood, Jonathan Way, Fiona Woollard, Chris Woodard, and especially Jonathan Dancy, Brad Hooker, Mike Ridge, Philip Stratton-Lake and Debbie Roberts.
} 


\section{References}

Adams, R. M. (1999). Finite and Infinite Goods: A Framework for Ethics. New York: Oxford University Press.

Aristotle. Nicomachean Ethics.

Arneson, R. J. (2010). “Good, Period.” Analysis 70(4): 731-44.

Bobonich, C. (2002). Plato's Utopia Recast: His Later Ethics and Politics. Oxford: Oxford University Press.

Brewer, T. (2009). The Retrieval of Ethics. Oxford: Oxford University Press.

Dancy, J. (2007a). "Defending The Right.” Journal of Moral Philosopby 4: 85-98. (2007b). "Moore's Account of Vindictive Punishment: A Test Case for Theories of Organic Unities." In S. Nuccetelli and G. Seay, eds. Themes from G. E. Moore: New Essays in Epistemology and Ethics. Oxford: Oxford University Press, pp. 32542.

Darwall, S. (2006). "Reply to Feldman, Hurka, and Rosati." Philosophical Studies 130: 63758. (2004). Welfare and Rational Care. Princeton: Princeton University Press.

Feldman, F. (2004). Pleasure and the Good Life: Concerning the Nature, V arieties and Plausibility of Hedonism. Oxford: Oxford University Press.

Fletcher, G. (2012). "Resisting Buck-Passing Accounts of Prudential Value.” Philosophical Studies 157: 77-91.

(2009). "Review of Richard Kraut's What Is Good and Why: The Ethics of Well-Being. Analysis 69: 576-78.

(2008). "Mill, Moore, and Intrinsic Value." Social Theory and Practice 34: 517-32.

Foot, P. (2000). Natural Goodness. Oxford: Oxford University Press.

Geach, P. (1956). "'Good and Evil." Analysis 17: 33-42.

Hooker, B. (1998). "Does Moral Virtue Constitute a Benefit to the Agent? In R. Crisp, ed. How Should One Live? Oxford: Oxford University Press, pp. 141-55.

Hurka, T. (2003). "Moore in the Middle." Ethics 113: 599-628. (1998). "Two Kinds of Organic Unity.” The Journal of Ethics 2: 299-320. (1987). "'Good' and 'Good For.”' Mind 96: 71-3.

Kagan, S. (2009). "Well-Being As Enjoying the Good." Philosophical Perspectives: Ethics 23: 253-72.

(1992). "The Limits of Well-Being." Social Philosophy and Policy 9(2). 169-89.

Korsgaard, C. (1983). "Two Distinctions in Goodness." Philosophical Review 92: 169-95.

Kraut, R. (2007). What Is Good and Why: The Ethics of Well-Being. Cambridge, MA: Harvard University Press. (1989). Aristotle on the Human Good. Princeton: Princeton University Press.

Lawrence, G. (2006). "Human Good and Human Function." In R. Kraut, ed. The Blackwell Guide to Aristotle's Nicomachean Ethics. Oxford: Blackwell, pp. 37-75.

McDowell, J. (1980). “The Role of Eudaimonia in Aristotle's Ethics.” In A. Rorty, ed. Essays on Aristotle's Ethics. Berkeley, CA: University of California Press, pp. 35976.

Moore, G. E. (2000/1903). Principia Ethica, revised edition. T. Baldwin, ed. Cambridge: Cambridge University Press.

Nagel, T. (1980). "Aristotle on Eudaimonia." In A. Rorty, ed. Essays on Aristotle's Ethics. Berkeley, CA: University of California Press, pp. 7-14.

Overvold, M. (1980). "Self-Interest and the Concept of Self-Sacrifice." Canadian Journal of Philosophy 10: 105-18.

Plato. Apology. . The Republic.

Portmore, D. (2007). "Desire-Fulfillment and Posthumous Harm." American Philosophical Quarterly 44: 27-38.

Prichard, H. A. (2002/1937). "Moral Obligation.” In J. MacAdam, ed. Moral Writings. Oxford: Oxford University Press, pp. 163-225.

Raz, J. (2000). "The Central Conflict: Morality and Self-Interest.” In R. Crisp and B. Hooker, eds. Well-Being and Morality: Essays in Honour of James Griffin. Oxford: Oxford University Press, pp. 209-38. 
(1995). "Duties of Well-Being." In J. Raz. Ethics in the Public Domain: Essays in the Morality of Law and Politics. Oxford: Oxford University Press, pp. 3-28.

Regan, D. (2004). "Why Am I My Brother's Keeper?” In R. J. Wallace, et al., eds. Reason and V alue: Themes from the Moral Philosophy of Joseph Raz: Oxford: Clarendon Press, pp. 202-30.

Rosati, C. (2009a). "Relational Good and the Multiplicity Problem." Philosophical Issues: Metaethics 19: 205-34. (2009b). "Self-Interest and Self-Sacrifice." Proceedings of the Aristotelian Society 109: 311-25.

(2008). "Objectivism and Relational Good." Social Philosophy and Policy 25: 314-49.

Scanlon, T. M. (1998). What We Owe to Each Other. Cambridge, MA: Harvard University Press.

Schroeder, M. (2007a). “Teleology, Agent-Relative Value, and 'Good.”' Ethics 117: 26595.

(2007b). Slaves of the Passions. Oxford: Oxford University Press.

Sobel, D. (1998). "Well-Being As the Object of Moral Consideration." Economics and Philosophy 14: 249-81.

Sumner, L. W. (1996). Welfare, Happiness and Ethics. Oxford: Clarendon Press.

Thomson, J. J. (2003). "The Legacy of Principia." The Southern Journal of Philosophy 41: 6282.

Williamson, T. (2007). The Philosophy of Philosophy. Oxford: Blackwell. 